diseases-then we can discuss cancer more studies of Horster and Thurau ${ }^{5}$ add some freely.-I am, etc.,

Burnham, Bucks

ROBERT GREEN

SIR,-I wholeheartedly agree with all that Mr. Charles Wright said in his Personal View (6 October, p. 45). I have always felt that if a patient asks for the diagnosis, whatever it may be, we have no right to withhold this information, with a full discussion of its implications. What right have we to lie to and deceive our patients? Most doctors are quite willing to explain to a patient the significance of an illness which may be of a much more serious nature than many carcinomas; and yet, when cancer is the diagnosis, they immediately start hedging and even deceiving. One result of this is that a distrust and strain develops between the patient and the doctor and between the family and the patient. The other consequence is to perpetuate the fear of cancer in the general public and to set it apart as a dreadful and frightening illness which should not even be spoken about, even though the outlook for many patients may be excellent. But even for those less fortunate, a frank and honest explanation will do a lot to help the patient to come to terms with his illness.

I often feel that many doctors are evading their duty and responsibility to the patient by maintaining their silence and taking the "easy way out," and all their reasons given for their policy of silence are merely poor rationalizations. A full explanation to the patient involves time and effort and a continuing support, which many doctors are not willing to undertake. I am fully aware that there are occasions when information may be harmful to the patient and should be withheld, but I am convinced that these are the exception rather than the rule.-I am, etc.,

London Hospital.

ANDREW P. WARIN

London E.1

\section{Ascites and Oedema in Liver Disease}

SIR,-We read the article by Professor $M$. S. Losowsky and Dr. B. B. Scott (11 August, p. 336) with interest, though some of the evidence they quote is in fact the subject of considerable disagreement in the literature. In particular we refer to the controversy surrounding the use of the xenon washout technique as a measure of the intrarenal distribution of blood flow. Kew et al. ${ }^{1}$ interpret the first component as a measure of outer cortical flow and the second component as a measure of juxtamedullary and outer medullary flow, whereas the Boston group, ${ }^{2}$ who appear to have had far more experience with the technique than anyone else, prefer to equate the first component with total "cortical flow." There are also a large number of theoretical objections to the technique, which have been well summarized by Britton et al. ${ }^{3}$ and Stein et al. ${ }^{4}$ The latter writers have concluded that this technique is valid only as a measurement of total cortical flow and does not discriminate changes in regional blood flow in the kidney.

The concept that juxtamedullary nephrons may be "salt retainers" and outer cortical nephrons may be "salt excretors" is also by no means established. The micropuncture support to this concept, but other work suggests that natriuretic states are associated with redistribution of blood flow to the long juxtamedullary nephrons. This was the conclusion reached by Wallin et al., ${ }^{6}$ using the anti-glomerular basement membrane antibody technique in rats undergoing an acute saline diuresis, and by Stein et al., ${ }^{7}$ using microspheres in dogs but with natriuresis induced by bradykinin or acetylcholine. In man Britton and Brown, ${ }^{8}$ using a modified renography technique, came to the same conclution in studies after chronic salt loading Others have failed to find any redistribution of blood flow in relation to natriuresis-for example, Blantz et al., ${ }^{9}$ using the antiglomerular basement membrane antibody technique in rats after chronic salt loading.

Finally, we feel that the comments on spironolactone underestimate its value in the management of ascites. In our experience low salt intake and spironolactone alone will induce a satisfactory diuresis in many patients, though doses of $400 \mathrm{mg}$ or more daily may be required. The main problem, as in any diuretic treatment in ascites, is the frequency with which uraemia and electrolytes disturbance develop.-We are, etc.,

\section{S. P. WILKINSON} V. ARroyo

Liver Unit,

Kings' College Hospital,

ROGER WILLIAMS

Department of Gastroenterology,

Central Middlesex Hospital

London N.W.10.

1 Kew, M. C., et al., Lancet, 1971, 2, 504.

cine, 1970, et al., Britton, K. E., Browr

M. M., Lancet, 1971,, N. J. G., and Bluhm, Stein, J. H., Boonjarern, S., Wilson, C. B., and (Suppl. I), p. 61

5 Horster, M., and Thurau, K., Pfügers Archiv für die gesamite Physiologie, 1968, 301, 162 Wallin, J. D., et al., American fournal of Physiology, 1971, 221, 1297

Stein, J. H., Ferris, T. F., Huprich, J. E., Smith, Investigation, 1971, 50, 1429 . $\mathrm{N}$. G Cinical Renography. London, Lloyd-Luke, 1971.

9 Renography. London, Lloyd-Luke, 1971. C., and Selbin, D. W. Wournal of Clinical Investigation,
$1972,51,2790$.

\section{Suction Drainage in Breast Surgery}

SIR,-Your leading article about wound healing in breast surgery (15 September, $p$. 554) gives me an opportunity of writing down what I believe to be an important practical point. Skin necrosis after mastectomy is, in my view, almost always due to the skin flaps being too thin and undermined too far. This is invariably because too little skin has been removed with the specimen, usually because of an inordinate fear of tension on the suture line. If the flaps are short and thick no amount of tension will produce necrosis-indeed, the greater the tension, the less is the chance of a tiresome collection of fluid. If the flaps are always planned to produce uniform moderate tension, healing by first intention can literally be guaranteed. In addition, the greater area of skin removed probably means a lower risk of local skin recurrences later. In our present state of ignorance about the proper operation for curable breast carcinoma it is essential that, whatever operation is chosen, morbidity should be minimal.

While applauding the principles of suction drainage and also the application of controlled trials, I doubt whether the type of drainage is of first importance in the healing of mastectomy incisions.-I am, etc.,

Basingstoke District Hospital,

R. J. HEALD

Basingstoke, Hants

\section{Methyldopa and Depression}

SIR,-I have read with interest the report of Dr. C. J. Bulpitt and Professor C. T. Dollery (1 September, p. 485). This report from such an authoritative source as the Royal Postgraduate Medical School will carry great weight. Therefore I feel it important to record that the experience of many of us does not agree with their statement in their summary that impotence and depression "were not related to methyldopa therapy." Indeed, in some cases diarrhoea and postural hypotension can also be induced by this otherwise most valuable drug.

I understand that Dr. Bulpitt and Professor Dollery are simply reporting the results of their own study and that only 287 patients on methyldopa were involved. Unfortunately I cannot produce statistics as our large number of hypertensive patients presents a problem of analvsis that has proved to be beyond available resources. However, there is no doubt about my clinical memory, which is confirmed by other members of staff and indeed other colleagues elsewhere.

In the past 14 years I have seen over 2,000 hypertensive patients and have used methyldopa very extensively in their treatment since it became available in the early 1960s. I can recall a considerable number of patients with depression on methyldopa. This was not present before treatment and cleared promptly when the treatment was changed. Not infrequently the chage in mood was noticed by the doctor, the patient denying it until his regimen was changed, when he and his spouse expressed gratitude for the great improvement in wellbeing. Naturally cases of this type would not appear in a self-administered questionnaire as they would not be self-recognized. Moreover, I feel that there may be a tendency for patients to deny symptoms of depression even when they recognize them.

My depressed patients were not necessarily on large doses of methyldopa. Even though it may be uncommon, I am sure that there is a real association between depression and this drug and that it is important to be alert to this possibility and be prepared to change to a happier regimen of treatment where necessary.-I am, etc.,

Papworth Hospital.

H. A. Fleming Cambridge

SIR,-Dr. D. Pariente (13 October, p. 110) challenges one of the conclusions in our article concerning the side effects of hypotensive agents (1 September, p. 485)namely, that methyldopa is not associated with an increased prevalence of depression. 